\title{
The Santa Barbara Wellness Project: Development and Implementation
}

\author{
Melissa L. Morgan Consoli, J. Manuel Casas, A. Patricia Cabrera, \\ and Gustavo Prado
}

University of California, Santa Barbara

\begin{abstract}
This article discusses the creation, implementation and maintenance of the Santa Barbara Wellness Project. This initiative was developed in response to an increase in Latino teen suicides in Santa Barbara County in recent years. Community members including mental health professionals, university faculty and students, concerned citizens, youth and parents came together to help form a prevention program in the wake of this adversity. A basic program including components of relaxation, stress management, problem-solving, and decision-making was developed through consultation among these groups and modifications continue as needed. The program is rooted in the empowerment philosophy of Freire $(1973,2004)$. Thus far, over 500 individuals have been trained and we are in the process of conducting program evaluation. Challenges, "lessons learned," and successes are discussed.
\end{abstract}

Keywords. wellness, prevention, community-based research, strengths, social justice

In the Fall of 2009, four Latino teens took their own lives in the county of Santa Barbara, California. This was noted to be a part of an increase in teen suicides in the area. In fact, the number of suicides overall had doubled for Santa Barbara County over the previous two years. As a part of the community response to these events, the Santa Barbara Wellness Project was formed. From the perspective of prevention, the project defines its mission in the following way: "The purpose of this project is to contribute to the wellbeing of children, adults, and families in the county of Santa Barbara. We will do this by bringing the community together to 
celebrate and build upon our life strengths and successes to overcome adversity. The goal is for all community members to live better and support and share lifestyles of wellness." The statement was developed by community members at a group meeting and is influenced by the desire to increase social justice in the community. The original "core group" members of the project have strived to perpetuate this aim through community collaboration and teamwork in the over two years that it has been in existence.

Since its inception, the project has provided wellness trainings to over 500 parents and youth in Santa Barbara and is currently branching into other parts of the county; however, the process of developing this community-based initiative has not been without its challenges. This article discusses the creation and implementation of this project, including rationale and theoretical underpinnings of the trainings inherent in the project, as well as the challenges and successes experienced in its implementation. The intent of this article is to provide information on the process of implementing this community-based initiative. While no formal evaluation of the project has yet been completed, feedback and reflections on this community based initiative provided by participant members are presented.

\section{Adversities Faced by Latino/a Youth}

A significant number of Latino/a youth, like many other ethnic and racial minority youth, find themselves over-represented in the low socioeconomic status (SES) population of the U.S. (Kulis, Marsiglia, Sicotte, \& Nieri, 2007; Stein, Jaycox, Kataoka, Rhodes, \& Vestal, 2003). Given this situation, these youth face a social and economic environment of inequality that includes greater exposure to life stressors such as racism, discrimination, violence, poor living conditions and limited access to social, educational and health related resources. Living in poverty in particular has a significant effect on the rates of mental illness. Persons in the lowest strata of income, education, and occupations are about two to three times more likely than those in the highest strata to have a mental disorder (U.S. Department of Health and Human Services, 2001).

Living in poverty also impacts social and family interactions. For example, many Latinas are forced to choose between work and taking care of their families, either limiting the time spent with their children, or seriously impacting their financial resources (Ornelas, Perreira, Beeber, \& Maxwell, 2009), parenting styles (Leidy, Guera, \& Toro, 2010), and time to seek out other social support networks. Research has shown that Latino/a families experiencing economic hardship endure conflict and tension in their family relationships, and as a result seek social support outside of the family context (Gomel, Tinsley, Parke, \& Clark, 1998). Social support appears to moderate the relationship between depression for first generation Latina mothers living in poverty and their children's internalizing behaviors (i.e., feelings of sadness, detachment, confidence levels) (Dennis, Parke, Coltrane, Blacher, Northwick-Duffy, 2003).

Many youth of color experience multiple incidences of discrimination and racism (Espino \& Franz, 2002), which occur for many reasons, including physical appearance and accent, low English proficiency, skin color, and/or negative stereotypes (Yeh et al., 2003). Such encounters with discrimination have been found emotionally, psychologically, and physically harmful to Latino/a individuals and to interfere with daily life (Alamilla, Kim, \& Lam, 2010). For example, individuals might avoid certain activities or situations that place them at risk for being discriminated against, such as going to a mall or a place where security is involved (Ornelas et 
al., 2009; Parra-Cardona, Sharp, \& Wampler, 2008). In more extreme cases, children may not want to go to school because of fear of discrimination.

Latino/a youth, like many other youth, encounter adversities in the form of gang exposure (violence) (Pew Hispanic Center, 2009). A large proportion of gang members in the U.S. tend to be Latino/a (Suárez-Orozco \& Suárez-Orozco, 1995). The Latino/a population exhibits several of the risks for gang involvement in that they are relatively younger, less educated, and reside in higher poverty areas as compared to the non-Latino/a White population (U.S. Census Bureau, 2006).

In the area of mental health, Latino/a youth may experience a range of psychological problems (Capps, Castañeda, Chaudry, \& Santos, 2007) due to the challenges noted above that include a high distrust of institutions and authority figures, fear of school, acting out behaviors, lowered aspirations and expectations, difficulties in school performance (Suárez-Orozco, 2007) and dropping out of school (Capps et al., 2007). In in-depth interviews with Latino/a students, teachers, and counselors at an alternative high school and within at-risk programs in regular high schools in a city in the Southwest, teachers did not hold high expectations for Latino/s students, and consequently students underperformed, had lower educational aspirations, and perceived school to be academically unchallenging (Fairbrother, 2008).

Low educational attainment is related to the above factors and is higher in Latino/a students than any other racial/ethnic group in the U.S. (Pew Hispanic Center, 2009). Various issues have contributed to the increasing dropout rates among Latino/a students, including poverty, pregnancy, poor academic achievement, parent's low educational attainment, lack of motivation, low aspirations, disengagement from learning, and single-parent households (Vélez \& Saenz, 2001). Additionally, Latino/a immigrant youth have been found to experience added stress, anxiety, and confusion upon entering a U.S. school and learning a new language (Vélez and Saenz, 2001), which may suggest that they face more challenges at school, contributing to subsequent dropout.

\section{Protective Factors and Resources for Latino/a Youth}

Individual, family, and community level protective factors promoting positive youth development are important to highlight in addition to risk factors (Rodriguez \& Morrobel, 2004). Positive adaptive behaviors, attitudes, and skills allow youth to cope with adverse situations and maintain normal functioning (Garmezy, 1993; McWhirter et al., 1998).

One protective resource for at-risk Latino/a youth is the presence of a mentor or other caring adult (Fairbrother, 2008). This mentor may be in the youth's family or outside of the family. For example, in-depth interviews with Latino/a undergraduate students revealed that a close relationship with their mother helped them to overcome obstacles, further their education, and succeed academically (Cabrera \& Padilla, 2004). In light of these findings, it has been suggested that parents, families, schools, peer groups, and communities work together to create opportunities for at-risk youth to develop caring adult relationships, in order to increase protective factors and decrease risk factors (Kuperminc, Wilkins, Roche, \& Alvarez-Jimenez, 2009). This may be accomplished through school and community-based programs in which atrisk youth feel included, affirmed, and accepted. 
Similarly, social support, whether from peers or family, has been associated with positive psychosocial functioning and healthy behaviors among ethnically and racially diverse youth (Kuperminc, Blatt, Shahar, \& Henrich, 2004). Youths' perceptions of high parental monitoring and strong family ties have been associated with decreased involvement in problem behaviors, including substance use, violence, and risky sexual behavior (Kerr, Beck, Shattuck, Kattar, \& Uriburu, 2003). This highlights the important role that family support can play as a protective factor for decreased problem behavior among Latino/a adolescents.

Finally, youth with pro-social behaviors, attitudes, and affect may have an easier time coping with adverse situations and avoiding risky-behaviors (i.e., problems in school, school dropout, substance use, teen pregnancy, delinquency, and the onset of mental disorders) (McWhirter, McWhirter, McWhirter, \& McWhirter, 1998). Having a connection to others and making meaningful contributions to one's community also facilitate resilience (Eccles \& Appleton, 2002).

Several variables have also been found to moderate the effects of perceived discrimination on health and well-being in ethnic minorities in the U.S. For example, in a study by Moradi \& Risco (2006), sense of control was found to be a partial mediator between perceived discrimination and distress among a sample of self-identified Latinos/as. Similarly, a meta-analysis including studies with various ethnic minority populations in the U.S. concluded that social support positively affects the impact of perceived discrimination on mental health as well as active or problem-focused coping (Pascoe \& Richman, 2009). Parental support has also been found to moderate the relationship between experiences of discrimination and higher academic wellbeing in Latino/a youth (DeGarmo \& Martinez, 2006), while academic motivation appears to mediate the relationship between perceived discrimination and academic success in Latino boys (Alfaro, Umaña-Taylor, Gonzales-Backen, Bamaca, \& Zeiders, 2009).

Many of these protective factors have been goals for facilitation in Positive Youth Development (PYD) programs, defined as programs that achieve one of the following objectives: promoting bonding, fostering resilience, promoting social, emotional, and cognitive competence, promoting behavioral competence, fostering self-determination, fostering spirituality, fostering selfefficacy, fostering clear and positive identity, fostering belief in the future, providing recognition for positive behavior, providing opportunities for prosocial involvement or fostering prosocial norms (Catalano, Berglund, Ryan, Lonczak, \& Hawkins, 2002). Effective positive youth development programs have been shown to strengthen social, behavioral, cognitive, and moral competencies for at-risk youth; foster and increase their self-efficacy; increase healthy bonding among youth and adults; expand opportunities and recognition for youth; and provide structure and consistency in program delivery (Catalano et al., 2002).

\section{Community Based Prevention Programming}

Often, models for community based prevention programs derive from community psychology, social activism, liberation theory, and feminist theory and call for collaborations between professionals and communities, while still taking into account the realities of power distribution (Robertson, 2010). Such ideology proposes that true empowerment occurs when power is not "given" but taken by the community itself (Rappaport, 1985). Similarly it has been said that "resources empower; services do not." Rubin and Rubin (1986) point out that empowerment is one of the important concepts in community work. The goals of empowerment are in line with the philosophies of community work which emphasize people's power and participation, the raising of people's social consciousness, and the changing of the environment to eliminate the 
social constraints acting on people's lives. In this respect, empowerment from the facilitator's standpoint is a process whereby practice is focused on a set of activities which are expected to reduce powerlessness that is derived from discrimination or stigmatization (Ping-Kwongm, 1996).

Such philosophies are best enacted by helping the community to define its own problems and possible solutions while helping to remove barriers (Freire, 1973). Examples of such prevention programs include "Going for the Goal," which was implemented with 350 middle school students. The goal of the program was for students to set and achieve positive and reachable goals. The program consisted of ten workshops in which trained high school students and teachers provided resources to middle school students. Participants were able to learn about the obstacles they encountered and ways in which they could adaptively cope with such obstacles. Through a specific method called S.T.A.R (which stands for: Stop and chill out, Think about alternative actions, Anticipate the consequences and Respond with the best choice), participants were able to increase their abilities to obtain goals and achieve personal control (O'Hearn \& Gatz, 1999).

The Choices Program is another multi-systemic program designed to foster positive youth development and promote school success among urban adolescents of color (Vera, Caldwell, Clarke, Gonzales, Morgan, \& West, 2007). To develop the curriculum, a needs assessment was conducted in the form of focus groups to determine the needs of students, parents, and teachers. The prevention program consisted of eight, weekly, 45-minute sessions for youth and three sessions for parents. The program provided psychoeducational resources to youth which addressed identity exploration, self-esteem and self-worth, decision-making skills and peer pressure, career exploration and goal setting, and study skills. Parents were provided with resources on childrearing techniques, communication skills, providing academic support to their children, and stress management skills, while teachers were provided with resources on how to identify their students' mental health needs through a cultural lens. Ongoing and summative evaluations were conducted. Upon completion of the program, Vera and colleagues (2007) found an increase in students' self efficacy, socio-emotional competencies, decision-making skills, communication skills, confidence, and ability to de-escalate risky situations.

\section{Santa Barbara Wellness Project}

Utilizing basic philosophies (i.e., community empowerment, community as collaborators and partners) from successful programs such as those above, along with the underlying tenets of Freire's writings on community involvement (1973), the Santa Barbara Wellness Project has attempted to craft a program that addresses the needs of our specific community: not only specific challenges for Latino/a youth, but also general wellness. The training is directed towards empowering the participants to manage their lives more effectively. To this end, emphasis is given to the identification and examination of the possible causes and/or origins of the challenges which they face. More specifically, through dialogue and discussion, the participants are able to see and experience themselves as capable of knowing and defining their problems (Freire, 2004) and, in turn, of taking responsibility for using their knowledge as the basis for implementing realistic actions in pursuit of acceptable solutions. In helping the participants get to this point, every effort is made to adhere to the following learning precepts put forth by Freire (1970): 1) From the onset, a problem-posing learning approach that can result in actions is used. Emphasis is given to the development of a learning relationship in 
which the participants and the trainers are partners in an environment in which all participants, including the trainers, teach each other and, as such, learn from one another, 2) special attention is given towards engendering the belief that the participants are the experts and it is through their expertise that we all can learn and grow, and 3) efforts are extended towards helping the participants identify what it is that has helped them to survive and maintain and/or improve their lives. While the trainers may teach some skills (e.g., relaxation and decisionmaking), in the end the participants are the experts who must decide if and when to use such skills.

Complimenting this philosophy, the psychological model that drives our empowerment based wellness project is comprised of three major interacting psychological components (Singh, Pandey, \& Aggarwal, 2007). Specifically, the wellbeing model is designed to: enhance participants' knowledge of how one defines and plans a response to challenges, help the participants regulate emotional responses and accumulated stress through relaxation or other exercises that they might identify and prefer to use, and discuss and demonstrate how they have the where-with-all to identify and make use of their existing skills to respond to a problem (Kuperminc, Thomason, DiMeo, \& Broomfield-Massey, 2011). We have sought to use psychoeducation with the view that "knowledge is power" when facilitating trainings on lifestyles of wellness. Specifically, we hope that we are, together as a community, helping under-resourced people become aware of resources and create a plan of action as called for by Freire (1973). Additionally, we aspire to help transform the social systems in which these events take place (Vera \& Speight, 2003) through assessing the needs of the community during presentations and helping to empower participants to work towards social change.

To meet the needs of the participants, the scheduling and locations of the trainings are quite flexible. Trainings are approximately one hour long and are offered in either Spanish or English, depending on the preference of the audience. An approximately equal number of Spanish and English speaking individuals have participated in wellness trainings, and participants have been either English speaking, Spanish speaking, or bilingual (Spanish and English) professionals, such as teachers, community workers and therapists, or members of our target community, i.e., parents, children and youth coming from neighborhoods that are primarily Latino/a and with a lower socio-economic background.

In the past two years, trainings largely have been provided by the original core group members. The original core group was comprised of five individuals: one first-generation Mexican immigrant, and four second- or third-generation (one Chinese, three Mexican) immigrants. All have had first hand, personal and professional encounters with the adversities faced by the community members receiving the training. In their professional capacity (e.g., youth-focused mental health worker, youth counselor in the juvenile justice system, multicultural psychologists or doctoral students specialized in working with Latino/as) all had established good working relationships with the community and with schools, non-profit agencies, and county mental health and social service departments. The trustworthiness and credibility of the trainers was greatly enhanced by the support and recommendations put forth by church leaders, school personnel, mental health personnel and community leaders. Once it was determined that the community was willing to partake of the training, (i.e., through the increased number of requests for training sessions) other concerned individuals from the community and the local university were recruited and trained to assume facilitation roles. 
All trainings start with discussion of community needs and strengths in the area of wellness and remain very interactive (i.e. not simply "lecture-style" presentation). In the discussion we try to facilitate a balance between the promotion of individual wellness and the collective goals of the community groups (Schueller, 2009). As mentioned above, all activities and discussions are implemented with the philosophy of community empowerment (i.e., Freire's philosophy), and finding and facilitating the expertise that community members currently possess for addressing personal and/or community problems. Therefore, to a large extent, each program is structured differently, according to the stated needs and of the specific group.

In the trainings three basic psycho-education concepts are presented: relaxation (including breathing exercises), problem-solving, and decision-making. Participants are encouraged to bring up examples from their own lives and communities. Usually this develops into a discussion and members share strategies they have learned or found helpful for achieving wellness. At the end of each training, participants are asked to share what they did or did not find helpful about the training, and their feedback is incorporated into the next training session. Some trainings have been designed as "one shot deals" while others have included follow-up visits for elaboration on particular topics. Settings have included Boys and Girls' Clubs, churches, ELAC (English Learners Advisory Committee) groups, alternative high school parent groups, alternative high school students, elementary school students, and mental health consumer groups.

\section{"Successes" and "Challenges"}

Thus far, responses to the trainings have been very positive, and participants have requested further training on related topics. The project was designed with the philosophy that the community is expert with respect to their needs, and community organizations with whom we have worked have seemed more willing to trust and work collaboratively when their feedback and input is sought from the very beginning of the training process and is valued and incorporated. The wellness team originally initiated relationships with community organizations by first asking what community members felt was needed and along the way helping to see that community needs were being met. This approach increased buy-in through helping to counteract previously formed community skepticism about outsiders coming in to their neighborhoods to offer "help." Some community organizations initiated contact with the wellness team after hearing positive feedback about the training from other community organizations.

As the project has grown, and more people have become involved, an important part of our initiative has been to maintain program fidelity by ensuring that all new participants provide trainings using the same philosophy and model as described above (for example, the overarching goal is empowerment, not hierarchical teaching). Prospective trainers are therefore required to attend two "train-the-trainers" meetings to become familiar with the training model. This entails attending and observing trainings being done with the community. In this training, prospective trainers observe the interactive nature of the groups. Once prospective trainers feel comfortable with this philosophy, they are asked to co-present with a more experienced presenter. Presenters are encouraged to adapt the materials to their own presentation style, without losing the goals and objectives of the training. Anyone is welcome to go through this process and become a trainer, and community members themselves (adults or youth) are especially encouraged to do so. Similarly, community members have been encouraged to be 
involved in the design of training materials.

From the onset, a major, but not unexpected, challenge that was faced by the wellness team was the need to bridge the gap between the perceived status of the trainers based on their level of professional expertise and the participants who took the initiative to attend the training sessions. As experts coming from the outside, bridging the gap essentially meant establishing trust, credibility, identity, and mutual respect and demonstrating a great deal of humility (i.e., no room for a "them and us" mentality"). In essence this meant addressing the power differential and demonstrating that the trainers could identify with the community and, more importantly, with each and every one of the participants. It meant that, through discussion, they could demonstrate a solid understanding of the challenges the participants face on a daily basis and that they could empathize with the continued frustrations that the participants experience in trying to address and overcome these stressful challenges (e.g., unemployment, racism, discrimination, violence, and limited resources, family conflicts, etc.). Two significant factors that helped the trainers bridge the gap were: 1) the personal and professional characteristics of the trainers (socio-cultural background, ability to speak Spanish, familiarity with the community, established working relationship with the community, trained helping professionals.); and 2) establishing the training program on Freire's philosophy (1970) that contends that learners have the "expertise" to understand the challenges (e.g., causes, origins) that they face as well as the "know how" to identify the most appropriate solutions to address such challenges (see Freire, 1970). Having such expertise, it follows that learners should be approached as equals and not as subordinates.

Thus far, we feel we have been able to maintain adherence to our original empowerment philosophies, however, not without difficulty. For example, community members have sometimes expressed hesitation in becoming facilitators of groups. This is likely for many understandable reasons, and our solution has been that we are currently working on a system of asking community members to "help" with (rather than lead) group facilitation to try to increase feelings of ownership and confidence, and decrease any potential anxiety.

Another challenge has been sustaining this initiative without any funds or resources. As aforementioned, people power has been a reoccurring issue and it may have been addressed through funds to hire more personnel. It has been evident that the members involved in this initiative have been committed because they have the genuine interest and motivation to help and give back to their community, but it has been difficult to instill and sustain this level of motivation in new volunteers considering that they are not receiving any financial incentives and that the initiative is time intensive.

\section{Perspectives from Participants}

In this section we will share the perspectives of some of our participants, including original members and others who have joined the group at later times during our two-year existence.

\section{Adult Parent Participant}

A female, adult participant was asked by interviewer about the effectiveness of the trainings. She stated, "Si, me sirvió de mucho. Ya mi hijo, gracias a Dios, tiene ya casi dos años que ya se porta bien. Y ya cambiamos el modo de ser, pues ... y el también pues con nosotros." (Yes, it 
served me well. Already my son, thanks to God, has already for almost two years behaved himself. And we already changed the way we live, since ... and also him with us).

\section{Graduate Student Member}

"My involvement in the community has brought meaning to my research and work with the Latino/a population. As I began working with "actual community members" through the realm of research, my genuine passion and motivation in helping to provide equal services and resources to the Latino/a community was re-ignited. I have learned as much or even perhaps more from the community members as they have from the trainings. This is not to say that there have not been any challenges as a doctoral student in balancing academia with community-based research and service: however, it is difficult to foresee myself conducting research programs without actually being in and returning to the community to present the program's research findings with the hope that it will help provide resources and skills. Though it has been challenging, those team members who continue to dedicate time and energy to this initiative are setting the stage for future researchers interested in prevention community-based research. Perhaps, the collaboration that currently exists between academicians and community members could inspire other academic personnel to venture into difficult, yet rewarding community-based research.

\section{Psychology Faculty Member/Community Based-Researcher.}

"This experience has taken a lot of hard work and tenacity but is really beginning to bear fruit. It is exciting that we are getting more and more word-of-mouth requests for wellness trainings and that people are showing interest in becoming "trainers." This initiative has been a way to give back to my community, provide students training in community-based research, and feel a part of a community-wide initiative. Although we have had our challenges, any sustainability we get from this project will be better than what was there before - nothing."

\section{Social Work Practitioner}

The Wellness Project has had quite a journey since it was first set into motion by the deaths of the four youths almost two years ago. What started as an effort by a couple of Juvenile Justice Mental Health practitioners to respond supportively to the neighborhood affected by the tragedies is evolving into a county-wide wellness project. Our evolution has encountered a few obstacles as the different participants - grassroots activists, parent groups, mental health practitioners and members of the university community - have needed to negotiate with one another to construct a space that welcomes all participants. But overall, I believe the efforts of the Wellness group are demonstrating that with hard work and commitment, our community can come together and heal in the face of overwhelming tragedy.

\section{Evaluation of the Project}

The general consensus for the project when talking to community members is that the program is "making a difference." While more formal evaluation of the Santa Barbara Wellness Project is planned, thus far our "evaluation" has been largely based on self-report from the participants and anecdotal information. Indicators of success in the informal evaluation thus far have included community members saying they value the groups, referring friends to the groups, and 
bringing their children to attend the groups. We have also had some enthusiasm about community members wanting to "take the training" to their own groups (although we have also had challenges with this aspect, as described above). This is particularly exciting as this was the mode we strive for - a self-sustaining, self-perpetuating program that the community owns. While we have not fully met this goal and continue to work on how to do so, both core group team participants and community participants agree that this enthusiasm seems a good indication of possible future success in this effort. We, and the community, also count the fact that so many individuals have been exposed to these ideas as "successful." Since there is always the chance that exposure to new ideas will create change, it seems at the heart of what our purpose is as a group.

All feedback by all participants has been taken into consideration in the continuing implementation of the program. At times, feedback has taken the form of suggestions which may help improve the program in the future. For example, a female adult parent participant stated, "... me gustaría poder participar para decirles a los padres que se presten porque no todos se prestan ... usted necesita tener mas orientación, mas información, para que pueda ayudar a [mi] hijo." (I would like to be able to participate to tell parents to get involved because not all parents get involved [in the program] ... you need to have more guidance, more information for me to help my son). In this case, we were able to further discuss with the participant what kind of "guidance" she wanted, and to subsequently plug more specific referrals into our resource list (i.e. substance abuse in teens). In another example, both youth and adult community members reported wanting more information and training on improving parent-child relationships. The wellness group was able to integrate this topic into the discussions more specifically by using tailored examples and discussion questions to encompass this issue more specifically. The wellness group continues integrating such relevant feedback into the program, in hopes of increasingly meeting the needs of community members and increasing the effectiveness of the program.

Planned formal program evaluation will include post-training surveys of participant satisfaction (i.e., what was helpful, what did you not know before, etc.) as well as follow-up focus groups for participants to elaborate on their process in going though the trainings and ways to improve the program. Input from community members in this process will be encouraged and valued. It is anticipated that this mixed methodological approach will capture both the concrete skills acquisition component as well as the process component of the participants' experiences. While this article was intended to discuss the implementation and maintenance of the program, the authors hope to report back to the field once this more formal evaluation has been completed.

\section{Conclusion}

The Santa Barbara Wellness Project is still in development and is constantly being revised based on feedback from community participants and group members. The program's philosophy of promoting the social justice values of equal access and distribution of resources, as well as community empowerment, has been a centerpiece of the project since its inception. While there have been specific challenges including lack of resources and difficulty passing on the "empowerment," many individuals' lives have been touched by this information. We often receive the feedback that people have never learned to relax or problem-solve before. Therefore, these basic skills seem to have much potential impact on peoples' ability to cope with adversity and maintain lifestyles of wellness. Additionally, the skills are being provided to 
individuals who are typically under-resourced and face many distinct life challenges. Currently, we are in the process of doing a program evaluation to gage how empirically "successful" the program has been. Whatever these results may bring, it feels clear to those of us in the program that impact is being made and we encourage other educators and mental health professionals to gauge and address the needs in your own communities, and bear with the challenges of designing and implementing a community based program. A little impact goes a long way.

Contact information:

Melissa Morgan Consoli

mmorgan@education.ucsb.edu

\section{References}

Alamilla, S., Kim, B., \& Lam, A. (2010). Acculturation, enculturation, perceived racism, minority status stressors, and psychological symptomotology among Latino/as. Hispanic Journal of Behavioral Sciences, 32, 55-76.

Alfaro, E.C., Umaña-Taylor, A.J., Gonzales-Backen, M.A., Båmaca, M. Y., \& Zeiders, K.H. (2009). Latino adolescents' academic success: The role of discrimination, academic motivation, and gender. Journal of Adolescence, 32, 941-962.

Cabrera, N. L. \& Padilla, A. M. (2004). Entering and succeeding in the "culture of college": The story of two Mexican heritage students. Hispanic Journal of Behavioral Sciences, 26, 152-170.

Capps, R., Castañeda, R. M., Chaudry, A., \& Santos, R. (2007). Paying the price: The impact of immigration raids on America's children. Washington, DC: Urban Institute. Retrieved from: www.urban.org/ UploadedPDF/411566_immigration_raids.pdf

Catalano, R. F., Berglund, M. L., Ryan, J. A. M., Lonczak, H. S., \& Hawkins, J. D. (2002). Positive youth development in the United States: Research findings on evaluations of positive youth development programs. Prevention \& Treatment, 5, 1-111.

Cervantes, R., Goldbach, J., \& Santos, S. M. (2011). Famila adelante: A multi-risk prevention intervention for Latino families. Journal of Primary Prevention, 32, 225-234.

DeGarmo, D.S., \& Martinez, C.R. (2006). A culturally informed model of academic well-being for Latino youth: The importance of discriminatory experiences and social support. Journal of Family Studies, 55, 267-278. 
Dennis, J. M., Parke, R. D., Coltrane, J. B., Blacher, J., Northwick-Duffy, S. A., (2003). Economic pressure, maternal depression, and child adjustment in Latino families: An exploratory study. Journal of Family and Economic Issues, 24, 183-202.

Eccles, J., \& Appleton, J. A. (Eds.). (2002). Community programs to promote youth development. Washington, DC: National Academy Press.

Espino, R., \& Franz, M.M. (2002). Latino phenotypic discrimination revisited: The impact of skin color on occupational status. Social Science Quarterly, 83, 612-623.

Fairbrother, A. (2008). "They might need a little extra hand, you know:" Latino students in atrisk programs. Urban Education, 43, 587-611.

Freire, P. (2004). Pedagogy of indignation. Boulder: Colorado, Paradigm.

Freire, P. (1973) Pedagogy of the oppressed. New York: Continuum.

Garmezy, N. (1993). Children in poverty: Resiliency despite risk. Psychiatry, 56, 127-36.

Gomel, J. N., Tinsley, B. J., Parke, R. D. \& Clark, K. M. (1998). The effects of economic hardship on family relationships among African-American, Latino, and Euro-American families. Journal of Family Issues, 19, 436-467.

Kerr, M. H., Beck, K., Shattuck, T. D., Kattar, C., \& Uriburu, D. (2003). Family involvement, problem and prosocial behavior outcomes of Latino youth. American Journal of Health Behavior, 27, S55-S65.

Kulis, S., Marsiglia, F. F., Sicotte, D., Nieri, T. (2007). Neighborhood effects on youth substance use in a southwestern city. Sociological Perspectives, 50, 273-301.

Kuperminc, G. P., Blatt, S. J., Shahar, G., Henrich, C., \& Leadbeater, B. J. (2004). Cultural equivalence and cultural variance in longitudinal associations of young adolescent selfdefinition, interpersonal relatedness to psychosocial and school adjustment. Journal of Youth and Adolescence, 33, 13-31.

Kuperminc, G. P., Wilkins, N. J., Roche, C., \& Alvarez-Jimenez, A. (2009). Risk, resilience, and positive youth developmental among Latino youth. In A. Villarruel, G. Carlo, J. M. Grau, M. Azmitia, N. J. Cabrera, \& T. J. Chahin (Eds.), Handbook of U.S. Latino psychology: Developmental and community-based perspectives (pp. 213-233). Thousand Oaks, CA: Sage Publications.

Kuperminc, G. P., Thomason, J., DiMeo, M., \& Broomfield-Massey, K. (2011). Cool girl, Inc.: Promoting the positive development of urban preadolescent and early adolescent girls. Journal of Primary Prevention, 32, 171-183.

Leidy, M.S., Guera, N.G. \& Toro, R.I. (2010). Positive parenting, family cohesion, and child social competence among immigrant Latino families. Journal of Family Psychology, 24, $252-260$. 
McWhirter, J. J., McWhirter, B. T., McWhirter, A. M., \& McWhirter, E. H. (1998). At-risk youth: A comprehensive response. Pacific Grove, CA: Brooks/Cole.

Moradi \& Risco (2006). Perceived discrimination experiences and mental health of Latino/a American persons. Journal of Counseling Psychology, 53, 411-421.

O'Hearn, T. C., \& Gatz, M. (1999). Evaluating a psychosocial competence program for urban adolescents. The Journal of Primary Prevention, 20, 119-144.

Ornelas, I.J., Perreira, K., Beeber, L. \& Maxwell, L. (2009). Challenges and strategies to maintaining emotional health: Qualitative perspectives of Mexican immigrant mothers. Journal of Family Issues, 30, 1556-1575.

Parra-Cardona, J.R.,Bulock, L., Imig, D.R., Villaruel, F., \& Gold, S. (2006).

:" Learning from the life experiences Mexican-origin migrant families. Family Relations: An Interdisciplinary Journal of Applied Family Studies, 55, 361-375.

Parra-Cardona, J.R., Sharp, E.A., \& Wampler, R.S. (2008). "Changing for my kid": Fatherhood experiences of Mexican teen fathers involved in the justice system. Journal of Marital and Family Therapy, 34, 369-387.

Pascoe, E.A. \& Smart Richman, L. (2009). Perceived discrimination and health: A meta-analytic review. Psychological Bulletin, 135, 531-554.

Pew Hispanic Center. (2009). Between two worlds: How young Latinos come of age in America. Washington D.C.: Pew Hispanic Center.

Ping-Kwongm, K. (1996). Empowering elderly people: A community work approach. Community Development Journal, 31(3), 230 - 240. Rappaport, J. (1985). The power of empowerment language. Social Policy, 16, 15-21.

Robertson, A. (2010). New health promotion movement; A critical examination. Philosophical Foundations of Health Education, 257-274.

Rodriguez, M. C., \& Morrobel, D. (2004). A review of Latino youth developmental research and a call for an asset orientation. Hispanic Journal of Behavioral Sciences, 26, 107-127.

Rubin, H.J. and Rubin, I.S. (2007). Community organizing and development (4 ${ }^{\text {th }}$ Edition). Boston, MA: Allyn \& Bacon.

Saleebey, D. (1996). The strengths perspective in social work practice: Extensions and cautions. Social Work, 41(3), $296-305$.

Schueller, S.M. (2009). Promoting wellness: Integrating community and positive psychology. Journal of Community Psychology, 37(7), 922 - 937. 
Singh, P., Pandey, A., \& Aggarwal, A. (2007). House-to-house survey vs. snowball technique for capturing deaths in India: A search for a cost-effective method. Indian Journal of Medical Research, 125, 550-556.

Stein, B. D., Jaycox, L. H., Kataoka, S., Rhodes, H. J., \& Vestal, K. D. (2003). Prevalence of child and adolescent exposure to community violence. Clinical Child and Family Psychology Review, 6, 247-264.

Suárez-Orozco, C. E., \& Suárez-Orozco, M. M. (1995). Transformations: Immigration, family life, and achievement motivation among Latino adolescents. Stanford, CA: Stanford University Press.

Suárez-Orozco, C. (2007, March). Commentary: The challenges of immigrant families. [Special section] Communiqué, 6-14. Washington, DC: American Psychological Association.

U.S. Census Bureau. (2006). Hispanic population in the United States, [Online]. Hispanics in the United States, Population Division, U.S. Census Bureau. Available: http://www.census.gov/population/www/socdemo/hispanic/files/Internet_Hispanic_in_U S_2006.pdf

U.S. Census Bureau. (2008). 2006-2008 American community survey 3-Year estimates. Population Division, U.S. Census Bureau. Retrieved from: www.factfinder.census.gov/servlet/DatasetMainPageServlet?program=ACS\&submenuId datasets2\&lang=en

Vélez, W., \& Saenz, R. (2001). Toward a comprehensive model of the school leaving process among Latinos. School Psychology Quarterly, 16, 445-467.

Vera, E. M, Caldwell, J., Clarke, M., Gonzales, R., Morgan, M., \& West, M. (2007). The choices program: Multisystemic interventions for enhancing the personal and academic effectiveness of urban adolescents for color. The Counseling Psychologist, 35, 779- 796.

Vera, E.M. \& Speight, S. (2003). Multicultural competence, social justice, and counseling psychology: Expanding our roles. The Counseling Psychologist, 31, 253-272.

Yeh, C. J., Arora, A.K., Onose, M., Okubo, Y., Li, R.H., \& Greene, P. (2003). The cultural adjustment and mental health of Japanese immigrant youth. Adolescence, 38, 481-500. 